\title{
LA MUSEALIZACIÓN, UNA VÍA PARA LA PRESERVACIÓN DE LOS SITIOS ARQUEOLÓGICOS EN CAMPECHE, MÉXICO
}

\section{MUSEUMS: A STRATEGY TO PRESERVE ARCHAEOLOGICAL SITES IN CAMPECHE, MEXICO}

\author{
Marisol Ordaz Tamayo ${ }^{1}$ y Juan Antonio Vázquez García ${ }^{2}$
}

\begin{abstract}
RESUMEN
México con una variada y rica diversidad cultural, oferta a nivel nacional e internacional su patrimonio histórico y cultural, incluyendo los sitios arqueológicos, los cuales son difundidos para su conocimiento, abriéndolos al público como tipo de museo, como monumento arqueológico o como un parque arqueológico. Hoy en día, varios de los sitios arqueológicos en el estado de Campeche, están expuestos sin la aplicación de lineamientos y requerimientos mínimos, sin planes de manejo que permitan una mejor operación, control, investigación y evaluación del sitio, esto hace que tampoco se genere una adecuada interpretación de los mismos, lo que causa el desconocimiento y la desvalorización de estos espacios como patrimonio arqueológico. La presente investigación surge a raíz de la problemática antes planteada y tiene como propósito establecer, a través del estudio y valoración de los sitios arqueológicos mayas de Campeche, a la musealización como vía para generar sensibilización y concientización sobre el patrimonio arqueológico con el fin de contribuir a la preservación del mismo, y a la Gestión del Patrimonio como elemento de integración entre la comunidad, patrimonio y turismo con el fin de generar el desarrollo sustentable de la región. Se propone que la puesta en valor de los sitios arqueológicos sea parte de una estrategia planificada multidisciplinaria con una intención de orden cultural, educativo, económico y turístico que contribuya al desarrollo sustentable de la región.
\end{abstract}

Palabras clave: Museos, zonas arqueológicas, cultura maya, preservación arqueológica

\section{ABSTRACT}

Mexico's long history and rich cultural diversity translates into an equally rich offer of national patrimony. That offer, both national and international in scope, adopts diverse formats, such as museums, archaeological monuments and/ or archaeological parks. Several Maya archaeological sites in the state of Campeche have been exposed without previous planning for their conservation, management, and further research. This leads to inadequate interpretation and, consequently, their devaluation as a priceless patrimonial heritage. This study explores the prospect and potential of a community and museum-based strategy as a key to integrate the value of said sites as educational, cultural, economic, and tourist assets and contributing factors to the region's sustainable development.

Keywords: Museums, Archaeological sites, Maya culture, Archaeological conservation

Tipología: Artículo de Investigación Científica y Tecnológica

Fecha de recepción: 18/02/2014

Fecha de aceptación: 17/07/2014

Forma de citar el artículo: Ordaz, T. M., \& Vázquez, J. A. (2014). La Musealización, una vía para preservar los sitios arqueológicos en Campeche, México. Jangwa Pana, 13, 34 - 50

1. Profesor Investigador de la Facultad de Arquitectura de la Universidad Autónoma de Yucatán. México. E-mail: otmayo@uady.mx

2. Investigador en la línea de conservación del patrimonio independiente. México. Correo: vazgaranju@hotmail.com 


\section{INTRODUCCIÓN}

$\mathrm{M}$ éxico como uno de los países en América Latina con mayor diversidad cultural, oferta a nivel nacional e internacional su patrimonio histórico y cultural. Esta situación ha originado la transformación de espacios naturales y sitios arqueológicos para musealizarlos, ya que son fuentes de conocimiento y cultura. En este sentido, los sitios arqueológicos son difundidos para su conocimiento, abriéndolos al público como un tipo de museo, como monumento arqueológico o como un parque arqueológico ${ }^{3}$, definido así en la Ley General de Museos en México. ${ }^{4}$

Esta investigación surge a raíz de la preocupación por la protección, preservación y conservación del patrimonio arqueológico en el estado de Campeche, al identificar la problemática en el manejo y operación que presentan los 17 sitios arqueológicos abiertos al público, así como las deficiencias encontradas en aspectos museísticos para su exhibición. Estos sitios están expuestos al público sin la aplicación de lineamientos y requerimientos mínimos, sin planes de manejo que permitan una mejor operación, control y evaluación del sitio. De la misma forma no generan un adecuado conocimiento e interpretación en los visitantes, causando el desconocimiento y la desvalorización de estos espacios como patrimonio arqueológico.

Esto nos lleva a determinar como objetivo de esta investigación, a la musealización como una vía para generar sensibilización y concientización sobre el patrimonio arqueológico con el fin de contribuir a su preservación y a la Gestión del Patrimonio como elemento de integración entre la comunidad, patrimonio y turismo, lo que hace necesario replantear la manera de exhibir los sitios abiertos al público bajo los lineamientos

3. Estatutos ICOM , Aprobados por la $16^{\mathrm{a}}$ Asamblea General del ICOM (La Haya, Países Bajos, 5 de septiembre de 1989) y modificados por la $18^{\text {a }}$ Asamblea General del ICOM (Stavanger, Noruega, 7 de julio de 1995) 4. De Ley General de Museos, presentada por el Ejecutivo federal, Miguel de la Madrid Hurtado, artículo 2 apartado III, IV, y V. diario oficial de la federación 1988 emitidos por el INAH y de manera multidisciplinaria, no solo para la puesta en valor del sitio de manera adecuada, si no también, para contribuir al desarrollo sustentable de la región donde se ubican estos sitios, gestionando la integración de empresarios turísticos, el gobierno y la comunidad, las nuevas formas de exhibirse al público deben incluir los objetivos como el de cualquier museo, sin fines lucrativos, al servicio de la sociedad, que adquiere, conserva, comunica y presenta con fines de estudio, educación y deleite los testimonios materiales del hombre y su medio, de dónde se desprenden las cinco actividades básicas que conforman la razón de ser de dichos centros: conservar, exhibir, adquirir, investigar y educar (ICOM, 1997: 3)

\section{La musealización y gestión del patrimonio}

Hoy día existe un gran número de asociaciones, organismos e instituciones académicas privadas y públicas, que se han dado a la tarea de establecer a nivel mundial la protección desde objetos hasta ciudades o grandes áreas naturales, que tiene un fuerte vínculo con la historia del hombre y su desarrollo. Esta situación ha generado una gran variedad de museos (ILAM, 2007: 8) para la exhibición de objetos o de interpretación de áreas, originando la evolución y transformación de estos espacios originalmente llamados museos.

Sin embargo, hablar de museos en la actualidad es referirnos a una gran variedad y tipos de espacios dedicados a la enseñanza y educación en la exhibición, no solo de objetos artísticos del pasado, sino de aquellos museos que ahora han abierto el espacio fuera de sus muros para contar historias. (Figura 1).

El museo se posiciona ahora como el principal vehículo de difusión, adquiriendo así una posición privilegiada que ha centrado una serie de investigaciones en las experiencias de aciertos y defectos de estos espacios. 


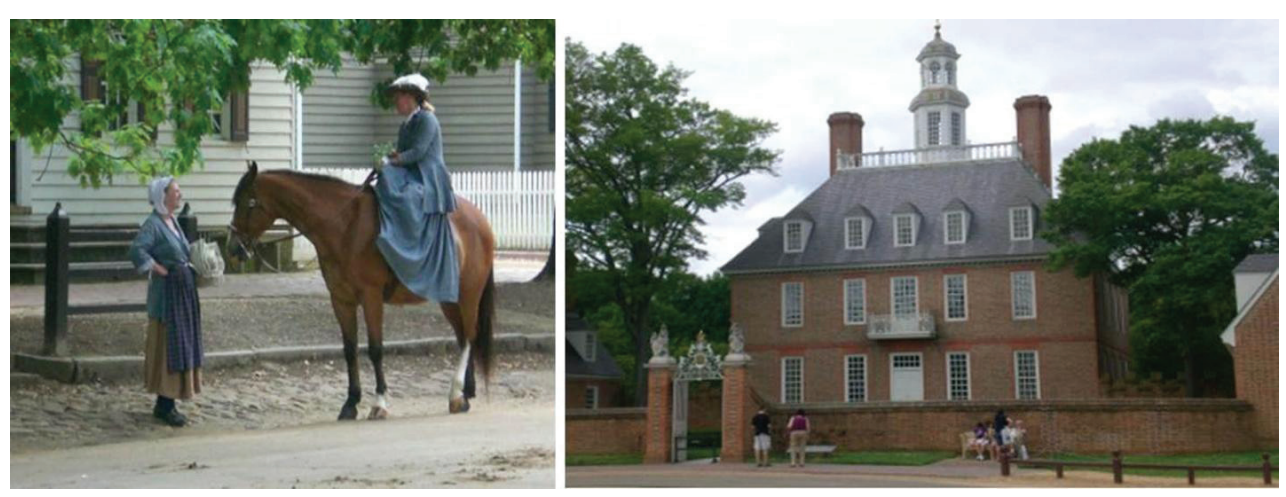

Figura 1. Williamsburg, modelo museístico. Modelo clásico de restitución en sitio. (Fuente: Juan A. Vázquez García).

En la actualidad con la apertura de nuevos museos apareció también la musealización, como una tendencia actual para mejorar el conocimiento e interpretación en los diferentes tipos de museos incluyendo a los sitios arqueológicos como nuevos museos fuera de muros. La musealización es una nueva forma de concebir a los museos, "es la puesta en valor del patrimonio (tangible o intangible) a través de la aplicación de un método."

La musealización comprende difusión, conocimiento, interpretación y valoración con sentido educativo y más aún, cuando el patrimonio tiene uso turístico. Lasheras \& Hernández (2004:129) considera que en el caso de yacimientos arqueológicos, musealizar es “...hacerlos visitables y accesibles, transformándolos en una exposición estable, como si de un museo se trata$r a$ ”. Este concepto se aplica en el lenguaje técnico de los investigadores y no se trata de convertir los sitios arqueológicos en una vitrina o panel, ni tampoco en show, no se trata de utilizar las funciones y mecanismos museológicos tradicionales, la función de la musealización es explicar por medio del discurso científico los acontecimientos del pasado y presente para todo tipo de público y de diferente nivel educativo, involucra al museo como espacio y a la museografía como la manera de establecer las técnicas para mostrar e interpretar al exhibir al público el objeto mueble o inmueble.

La interpretación y exhibición aunada a la investigación, son los aspectos que tiene que ver con la dimensión pública o social de la gestión del patrimonio (Ballart \& Juan, 2001: 23), la gestión se convierte en el elemento de integración entre la comunidad, el patrimonio y el turismo desde sus tres apartados: Planificación, Control y Difusión (Querol, 2010: 51-57). Todas sus acciones en sus diferentes ámbitos nos permiten entender que la cultura abraza el patrimonio tangible e intangible. La gestión del patrimonio como proceso de desarrollo basa sus criterios en la sostenibilidad cultural y ambiental, lo que también implica una adecuada gestión de recursos económicos como una vía posible para el desarrollo y protección de la cultura y desarrollo local. (Figura 2)

5. Definición de musealizción tomado de Lavert Proyectos culturales http://www.lavert.net/Expertos-en/Musealización 


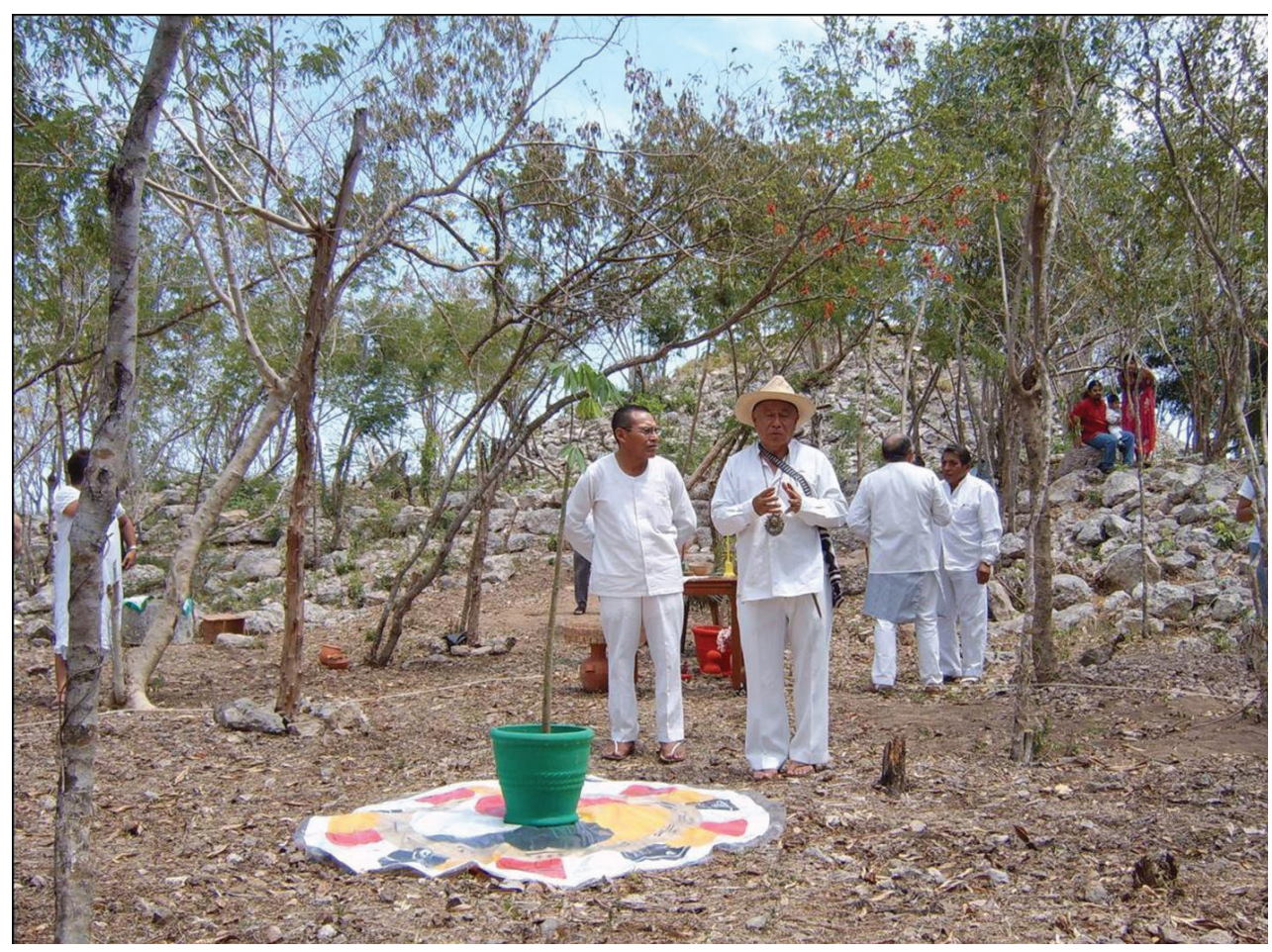

Figura 2. Ceremonia Maya. Puesta en valor del Parque arqueo ecológico Xoclán. (Fuente: Marisol Ordaz Tamayo).

\section{La musealización del patrimonio arqueológico en México}

La creciente demanda del turismo a nivel mundial, ha colocado al patrimonio de diversos países para uso turístico, esta situación ha mantenido una preocupación latente en la preservación y conservación a diferentes instituciones y organismos de carácter público y privado. Esta preocupación ha generado que se realicen diversos congresos, conferencias, reuniones académicas, etc. para la musealización del patrimonio con el fin de intercambiar experiencias sobre el impacto turístico en el patrimonio y su prevención. (Figura 3)

En México las acciones culturales más importantes son la preservación y conservación del patrimonio cultural, pero al mismo tiempo su difusión en el plano turístico, establecido así en el Plan Nacional de Desarrollo, considerando el impulso del turismo como eje de desarrollo por lo que se fortalece la visita pública con la difusión internacional de playas, ciudades históricas, tradiciones, costumbres, folklore y el patrimonio arqueológico como principal oferta turística.

Actualmente se encuentran abiertos al público 187 sitios arqueológicos ${ }^{6}$, lo que ha provocado que se transformen en áreas visitables, sin que se lle-

6. Instituto Nacional de Antropología e Historia (INAH). Catálogo de Sitios y Monumentos Arqueológicos última actualización en agosto de 2013. http://www.inah.gob.mx/zonas-arqueológicas 
gue a comprender el concepto de estos sitios como museos abiertos. Estas acciones que incluyen exponer las grandes estructuras monumentales que señorean los espacios urbanos prehispánicos al público, en la mayoría no han sido acompañadas de acciones preventivas para su visita pública, sólo sitios considerados de mayor importancia como Teotihuacán en el Estado de México, el Templo Mayor en la Ciudad de México, Monte Albán en Oaxaca, Palenque en Chiapas, Chichen Itzá y Uxmal en Yucatán entre otros, presentan un mejor proyecto museológico y museográfico incluyendo herramientas tecnológicas para su musealización, mostrando verdadera preocupación por presentarlos a la visita pública como un sentido educativo y turístico. Aquí cabe destacar la importancia que la musealización tiene para la puesta en valor de estos sitios, pues de ella se desprenden las primeras interpretaciones hechas en torno a la cultura prehispánica e indígena de nuestro país, que constituyen un bien patrimonial único e insustituible por su alto contenido testimonial. (Figura 4)

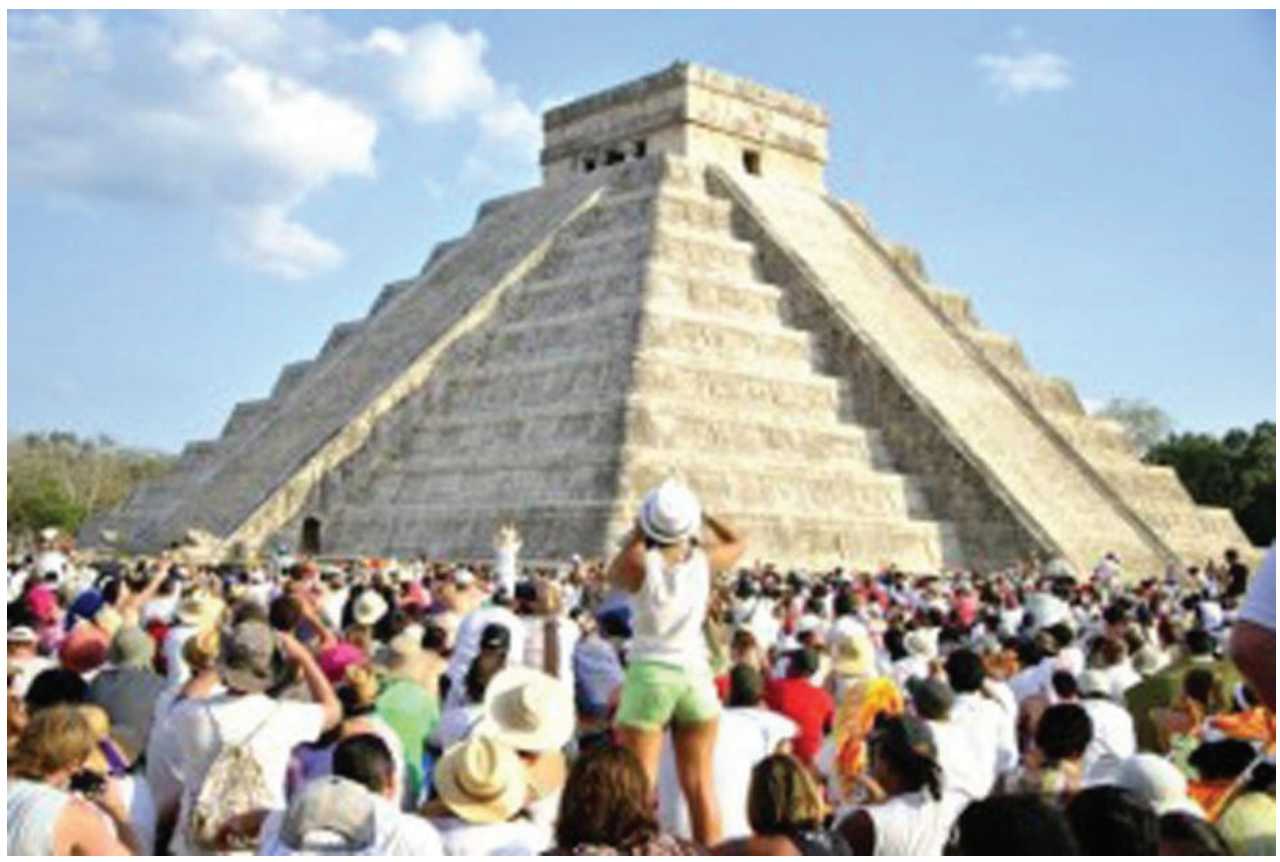

Figura 3. Equinoccio de Chichén Itzá, Yucatán (Fuente: Arqueología, Imagen, Diario de Yucatán. 28 de marzo de 2013).

La importancia de mostrar al público un sitio arqueológico, reside en promover un ambiente para el aprendizaje creativo $^{7}$ (Santacana \& Serrat, 2005: 430-431), buscando revelar al público el significado del legado cultural o histórico de los bienes que expone, orientados a cubrir cuatro funciones básicas las cuales se manejan de manera paralela en los objetivos de los mu-

7. Sostienen que para que el patrimonio arqueológico sea comprensible y que el museo cumpla con su objetivo de difusión, estos han de ser mostrados desde varias directrices didácticas 
seos, como lo especifica el ICOM-UNESCO ${ }^{8}$ : Investigación, conservación, divulgación y puesta en valor del objeto que lo constituye, sin embargo para exponerlos al público han de ser investigados y aprobados desde diferentes disciplinas, para garantizar la conservación, prever la capacidad de carga, establecer lineamientos de operación, control y manejo, así como la adecuada musealización con el fin de hacerlos visitables.

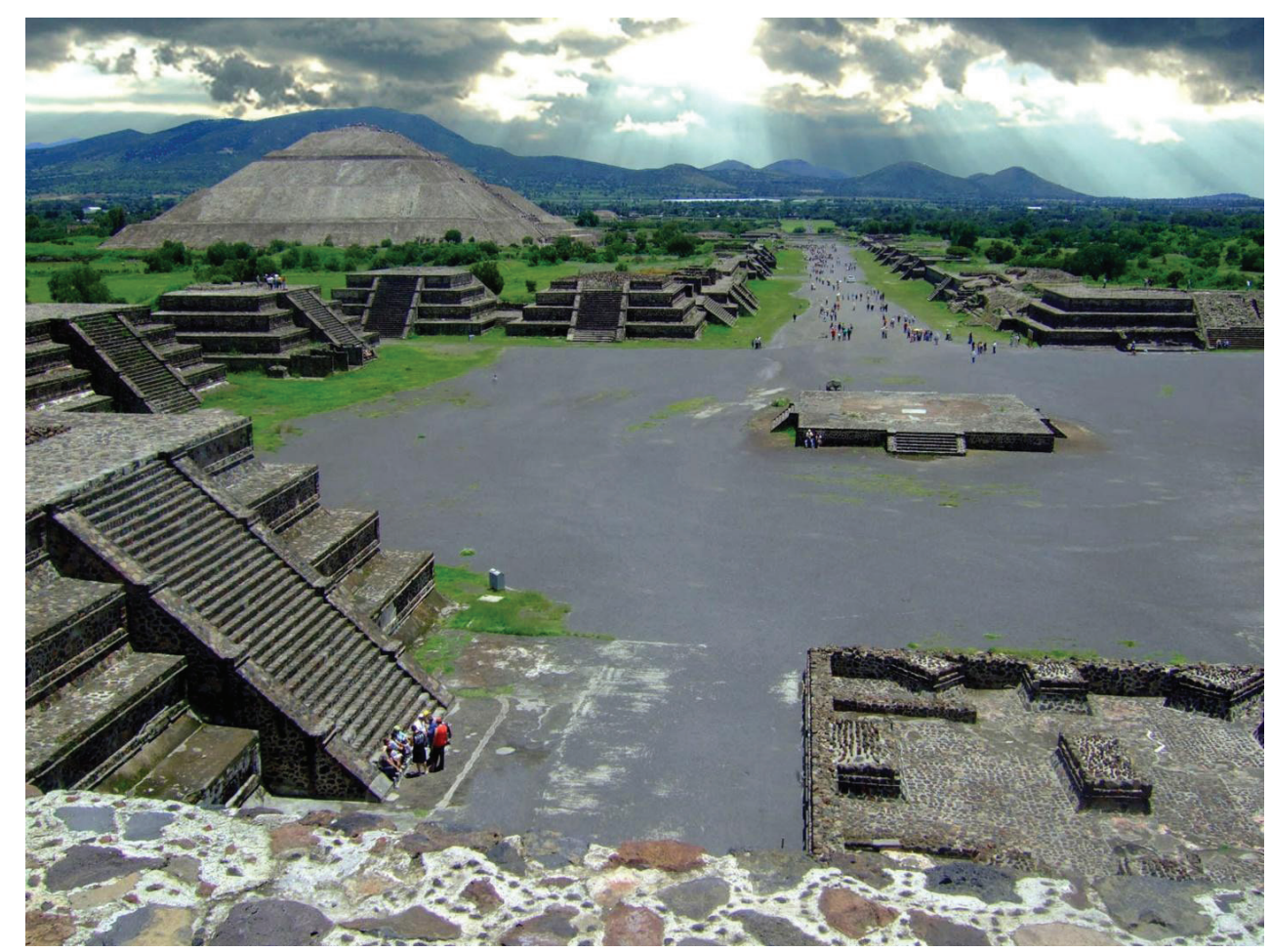

Figura 4. Sitio Arqueológico de Teotihuacán. (Fuente: Marisol Ordaz Tamayo).

Los organismos públicos, privados y los tres órdenes de gobierno difunden el patrimonio arqueológico con fines educativos y turísticos, lo que conlleva la obligatoriedad de constituir una sensibilización y concientización para preservarlo a futuras generaciones de los mexicanos y visitantes de todo el mundo. Este cometido lo expresa uno de los objetivos del INAH, "Preservar y difundir el patrimonio antropológico, arqueológico, paleontológico e histórico del país mediante la restauración, conservación, catalogación, registro y protección legal y la publicación de la producción académica, expansión y actividades de comunicación educativa", sin embargo, en la práctica está lejos de cumplirse este cometido.

8. Estatutos del ICOM, documento aprobado 24 de agosto de 2007 en Viena (Austria), p. 3 http://icom.museum/ fileadmin/user_upload/pdf/Statuts/statutes_spa.pdf

9. Diario Oficial de la Federación, México, 17 de enero de 2011 INAH, Manual general de organización del Instituto Nacional de Antropología e Historia. Objetivos estratégicos, p. 119 


\section{Lineamientos y requerimientos del INAH para la operación de los sitios arqueológicos en México}

El alto potencial turístico de los sitios arqueológicos ha ocasionado una demanda constante para abrir nuevos sitios por parte de diferentes instancias estatales y municipales, el INAH, órgano al que se la ha conferido la custodia y operación de las zonas arqueológicas en México, de conformidad con la Ley Federal sobre Monumentos y Zonas Arqueológicas, Artísticas e Históricas ${ }^{10}$, ha establecido la normativa ${ }^{11}$ para los sitios arqueológicos en tres acciones que van de la mano con la operación y funcionamiento:

\section{Lineamientos para el manejo y operación de zonas arqueológicas con visita pública}

Este lineamiento establece que el manejo y operación de una zona arqueológica implica la ejecución de acciones coordinadas de planeación; preservación y mantenimiento; conservación; investigación; protección jurídica y técnica; interpretación, educación y difusión; infraestructura y servicios; así como de administración necesarias para lograr su conservación integral a largo plazo. No debiendo poner en riesgo su conservación integral, ni comprometer su estado físico y sus valores.

El proceso de planeación se materializará en un plan de manejo, el cual se integrará con base en los términos de referencia y manual respectivos.

\section{Lineamientos para la apertura de zonas arqueológicas de visita pública}

En sus disposiciones generales, estos lineamientos establecen que la apertura de una zona ar-

10. Ley Federal sobre Monumentos y Zonas Arqueológicas, Artísticos e Históricos, Diario Oficial de la Federación, México, 6 de mayo de 1972. Última reforma publicada en el DOF el 4 de abril de 2012

11. Lineamientos para la elaboración de proyectos arquitectónicos, equipamiento y señalización en zonas arqueológicas. Instituto Nacional de Antropología e Historia, México, 22 de octubre de 2006 http://www.normateca.inah.gob.mx/documents/066.pdf queológica debe invariablemente realizarse en un marco de coordinación entre profesionales de diversas disciplinas y las áreas del INAH, cuya competencia e intervención estará determinada por las disposiciones de planeación que establecen los mismos lineamientos, debe llevarse a cabo bajo un marco de colaboración y coordinación con los Gobiernos Estatales, Municipales e Instituciones de la Federación facultadas por la Ley.

Para llevar a cabo el procedimiento de autorización para la apertura de zonas arqueológicas hay que mencionar la serie de puntos estratégicos para su apertura operación y manejo: Planeación y Campos de Manejo, Protección Jurídica y Técnica, Preservación y Mantenimiento, Investigación, Conservación, Administración Operación, Difusión, Educación y Capacitación, así como la Contribución al Desarrollo Regional.

El arqueólogo responsable de los sitios debe cumplir los lineamientos establecidos en el documento para su aprobación y autorización para su apertura basada en los siguientes criterios: a) La importancia científica de la zona arqueológica a nivel regional o nacional en términos de su excepcionalidad, representatividad, autenticidad e historicidad; b) La importancia cultural de la zona arqueológica con base en los significados, asociaciones y usos asignados por los actores sociales interesados en ella; c) La integridad y autenticidad de la zona arqueológica en relación con su potencial para la comprensión, presentación e interpretación de sus valores culturales; d) La estabilidad de sus componentes físicos y de sus entornos social y natural en relación con el impacto derivado de la visita pública; e) La situación de la tenencia de la tierra que ocupan los monumentos arqueológicos y las perspectivas para su regularización; f) La disponibilidad de vías de comunicación para el acceso a la zona arqueológica; g) Las prioridades de protección y conservación de patrimonio arqueológico existentes en la región; h) Las capacidades técnicas, administrativas, de investigación y conservación 
del INAH para atender la operación de las zonas arqueológicas de la región; i) La oferta existente de zonas arqueológicas abiertas al público en la región en relación con su significado y requerimientos que demanda la apertura de una zona arqueológica; y j) La ponderación del impacto derivado de la apertura de la zona arqueológica en el ámbito del desarrollo local.

\section{Lineamientos para la Elaboración de Proyectos Arquitectónicos, Equipamiento y Señalización en Zonas Arqueológicas}

Estos lineamientos se refieren técnicamente a la elaboración de proyectos arquitectónicos, equipamiento y señalización de los sitios y en él se instituye como objetivo principal: "Establecer los criterios fundamentales para el equipamiento y desarrollo de Proyectos arquitectónicos con alta calidad y funcionalidad en las zonas arqueológicas y su entorno, que respeten los lineamientos técnicos y normas jurídicas nacionales e internacionales aplicables" $" 12$. Además de establecer criterios con los que se debe señalizar una zona arqueológica, en términos de diseño gráfico e industrial, redacción de textos, materiales, emplazamientos e instalación. Estos mismos lineamientos tienen objetivos, fundamentos legales, ámbitos de aplicación en el territorio nacional y definiciones de conceptos, criterios generales, lineamientos particulares de ámbito federal y local en función a nuevos proyectos arquitectónicos, equipamiento y señalización tomando en cuenta que las controversias que se presenten sobre la interpretación de estos lineamientos, serán resueltas por la Dirección General del Instituto, con apoyo de las coordinaciones nacionales correspondientes. Los proyectos arquitectónicos que se generen al interior de las zonas arqueológicas tienen una evaluación dictaminada por el Consejo de Arqueología y una autorización de la dirección general del INAH.

12. INAH, Lineamientos para la elaboración de proyectos arquitectónicos, equipamiento y señalización en Zonas Arqueológicas, México, 29 de Noviembre de 2006, p. 3 http://www.normateca.inah.gob.mx/documents/070.pdf

\section{Los sitios arqueológicos de Campeche}

El estado de Campeche ocupa la parte suroeste de la península de Yucatán colindando al norte con el estado de Yucatán, al sur con el estado de Tabasco y la república de Guatemala, al oriente con el estado de Quintana Roo y al poniente con el Golfo de México. Alcanza una extensión territorial de más de $56,858.84 \mathrm{~km} 2$. Forma parte de las Tierras Bajas del norte-centro y Peten, su ocupación se remonta a 600 a.C. La evidencia arqueológica sugiere que sitios como Edzná, Becán y Calakmul surgen como pequeños poblados y posteriormente desarrollan diversas obras urbanas hasta configurar complejas ciudades (Campaña, 2005: 78).

Hacia el siglo III de nuestra era, la sociedad maya de las tierras bajas inició un periodo de grandes realizaciones en todos los aspectos de la cultura, y alcanzó altos niveles de excelencia en arquitectura, cerámica, astronomía, etc. A esta época, que termina en el siglo $\mathrm{X}$, se le conoce como Horizonte Clásico. Desarrollaron un estilo arquitectónico muy definido, el estilo Petén, el cual refleja una elevada complejidad social que permitió la individualización de esos grupos. Este hecho, que incluye toda la cultura, se manifiesta muy claramente en los edificios, que presentan como característica principal los grandes basamentos piramidales escalonados con las esquinas remetidas; escalinatas frontales de anchos peldaños, por medio de los cuales se asciende a un templo en la parte superior, coronado por un alto muro llamado crestería, decorado con figuras zoomorfas y antropomorfas realizadas en estuco policromo. Los sitios que presentan este estilo como Calakmul, Nadzcaan, Balamkú, Becán, El Tigre, El Palmar, Edzná y Acanmúl, suelen contar con edificios dispuestos en plazas bien definidas, existiendo un plan regulador general del sitio, un aglutinamiento ordenado de las estructuras con arquitectura monumental. Otro rasgo interesante de estos asentamientos es la abundancia de las inscripciones jeroglíficas sobre bloques monolíticos denominados estelas. (Peña, 1999: 45-46) 
Existen otras tendencias y estilos arquitectónicos de menores dimensiones, como el denominado Río Bec, Chenes y Puuc. Las dos primeras predominan en el sur y oriente de Campeche durante los siglos VII a IX, cuando se produce el clímax poblacional y arquitectónico. (Figura 5)

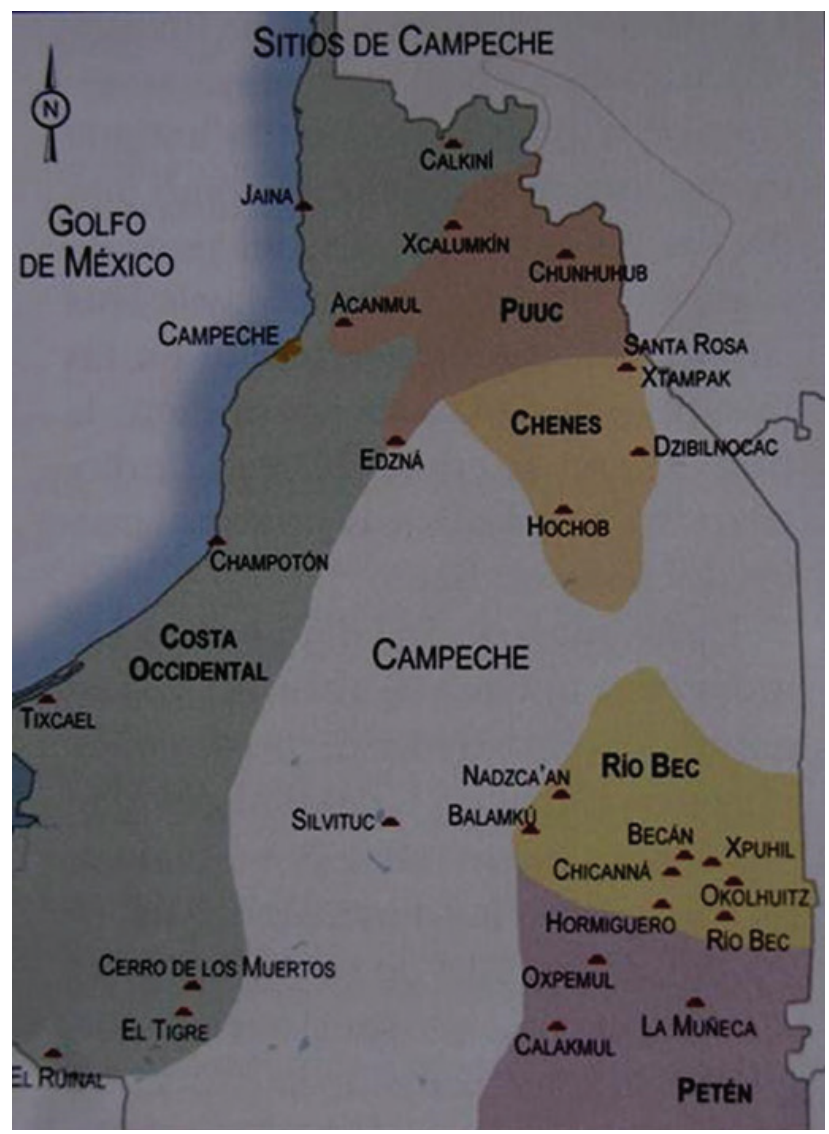

Figura 5. Plano de los sitios arqueológicos de Campeche y sus estilos arquitectónicos. (Fuente: Arqueología Mexicana, No. 25 (2007).

Tras la caída y abandono de las ciudades mayas del Petén ocurrieron movimientos migratorios del norte al sur de la península de Yucatán. Algo que se ha detectado en los sitios explorados por los arqueólogos del INAH, es la apreciación de la preocupación parcial de los espacios abiertos y la adecuación de viviendas rústicas al pie de las grandes estructuras, forma de vida semirural que no parece haber llegado hasta el siglo XIII. (Campaña, 2005: 78)
El INAH, delegación Campeche cuenta con un catálogo donde registra cerca de 1,500 sitios detectados en el estado, de los cuales 17 sitios están abiertos al público ${ }^{13}$, constituido en 5 rutas turísticas (Figura 6) donde puede apreciarse sitios con variedad de estilos arquitectónicos. Los sitios abiertos al público en las diferentes rutas de Campeche son: Balamku, Becán, Calakmul, Chunhuhub, Chiccaná, Dzibilnocac, Edzná, El Tigre, Hormiguero, Hochob, Kanki, El Tabasqueño, Santa Rosa Xtampac, Tohcok, Xcalumkin, Xpuhil. Con este número de sitios, Campeche se convierte en uno de los estados con mayor cantidad de sitios abierto a la visita pública. Esto se debe a la importancia y características que estos sitios tienen en la región donde se localizan y a la riqueza y variedad de estilos arquitectónicos que demuestran el florecimiento que tuvieron las ciudades mayas de esta región ${ }^{14}$

Sitios como El Tigre, Chicanná, Hormiguero, Hochob, El Tabasqueño, Chunhuhub, Santa Rosa Xtampac, Xcalumkin, Nadzcaan, eran sitios custodiados y en estado de restauración y conservación que presentaban notable saqueo y destrucción por los pobladores cercanos a estos vestigios, quienes comercializaban objetos cerámicos o utilizaban piedras de los restos arqueológicos (cuyos o montículos) para la construcción de sus viviendas. Estas situaciones fueron determinantes para proveerlos de equipamiento mínimo e integrar el expediente de autorización para la visita pública, con la intención de consolidar la preservación y conservación y abrirlos al público $^{15}$

Al Abrirse al público estos sitios conformarían los corredores o rutas arqueologías que hoy conocemos, con una variedad de estilos arquitectónicos como: Rio Bec, Peten y Chenes. Conformando hoy Balamkú, Calakmul patrimonio cultural de

13. CONACULTA, Red de zonas arqueológicas, http://www.inah.gob. $\mathrm{mx} /$ zonas-arqueologicas

14. Según lo han señalado los arqueólogos investigadores como Piña Chan y Morley, entre otros.

15. Gestiones hechas por el entonces delegado del INAH en Campeche Lic. Carlos Vidal Angles. 
la humanidad, Becán, Chicanná, Nadzcaan, Xpuhil uno de los corredor arqueo-turístico que se oferta turísticamente.

Hay que mencionar que los 17 sitios arqueológicos abiertos para el caso del estado de Campeche abrieron al público antes de la edición de la norma por el INAH en el año 2006, sin embargo, en la evaluación anual de los sitios arqueológicos y para la planeación del nuevo año la aplicación de esta normatividad no ha sido posible, el instituto responsable, se ha visto rebasado en su capacidad verificar el cumplimiento de la normatividad para su operación y control.

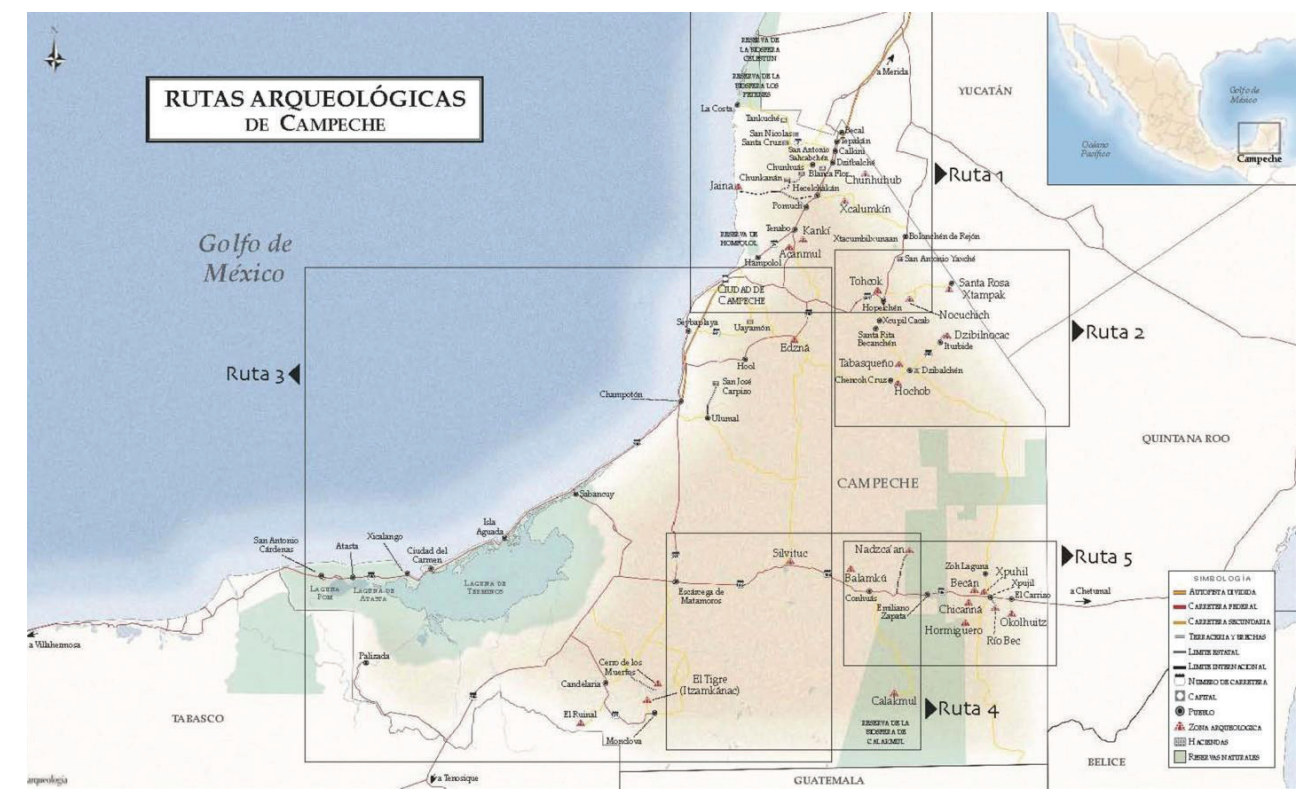

Figura 6. Plano de las rutas arqueológicas (Fuente: Arqueología Mexicana, №. 25 (2007)). Indicación de pueblos cercanos a sitios arqueológicos (Fuente: Juan Vázquez García).

Los sitios arqueológicos hoy día están expuestos al público sin una adecuada exhibición, sin la aplicación y el cumplimiento de lineamientos y requerimientos mínimos, sin planes de manejo que permitan una mejor operación, control y evaluación del sitio. No generando en el visitante un adecuado conocimiento e interpretación de los restos arqueológicos, causando el desconocimiento y la desvalorización de estos espacios como patrimonio arqueológico.

De acuerdo con los objetivos del sitio arqueológico, podemos poner en duda si estos como museo cumplen con su objetivo y en su caso plantearse preguntas como: ¿Existe una adecuada musealización de los sitios arqueológicos prehispánicos? ¿Quién musealiza los sitios arqueológicos tiene toda la capacidad para hacerlo? ¿Cuáles son las políticas de apertura, operación y manejo que se les da a los sitios arqueológicos? ¿Cuál es el objetivo e intencionalidad al presentarlo al público? ¿Cuál es el concepto y metodolo- 
gía que se aplica a los sitios arqueológicos para su apertura al público? ¿Debemos entenderlos e interpretarlo, como un museo, como un parque arqueológico o como un centro de interpretación arqueológica?

\section{MATERIALES Y MÉTODOS}

En esta investigación el establecer parámetros para el análisis y valoración de los sitios arqueológicos permitió un acercamiento para la identificación de la problemática en la musealización. Se llevó a cabo bajo un enfoque cuantitativo, descriptivo y explicativo, por lo que se utilizó la recolección y análisis de datos con el fin de contestar preguntas de investigación y probar que la musealización es una vía que puede contribuir a la preservación y conservación de los sitios arqueológicos de Campeche. Se centra el interés en explicar la situación que prevalece en la puesta en valor del patrimonio arqueológico del estado de Campeche, las condiciones en las que se da y la relación de variables analizadas.

Para la realización de la investigación fue necesario utilizar diversas técnicas e instrumentos para la exploración de los sitios y recolección de datos: investigación documental, encuestas, entrevistas y cédulas de registros.

El análisis de cada uno de los sitios arqueológicos de Campeche, así como el número de turistas registrados al año que visitan los sitios, fueron aspectos determinantes para seleccionar seis de los diecisiete sitios abiertos al público y establecer una metodología para su valoración.

\section{Valoración de los sitios arqueológicos de Campeche}

La visita a cada uno de los sitios arqueológicos de Campeche permitió conocer cuáles son sus fortalezas, amenazas, debilidades y oportunidades y poder seleccionar los sitios muestras para el análisis y saber si cumplen con los requerimien- tos para su puesta en valor al público y cumpla con el objetivo de cualquier museo. Los sitios muestran equipamiento mínimo para la visita pública y deficiencia en aspectos de musealización, situación que llevan a establecer un análisis a cada uno de ellos, en el cumplimiento de los lineamientos y requerimientos mínimos para los sitios arqueológicos con visita pública expuesto anteriormente emitidas por el INAH.

Realizar un análisis de todos los sitios arqueológicos de Campeche es una labor titánica, por lo que para realizar el diagnóstico de estos sitios, se diseñó una ruta que incluye 6 sitios de tres rutas turísticas diferentes de mayor importancia y visita pública (Figura 7). En cada sitio se realizó un registro fotográfico y cédulas de registro, que expresan claramente los servicios que ofrece, el área poligonal de la zona arqueológica, el equipamiento mínimo para su operación y funcionamiento a los visitantes y el cumplimiento de los lineamientos antes expuestos, se realizaron entrevistas y suministro de encuestas a usuarios y pobladores cercanos con el fin de determinar el grado de difusión, conocimiento del sitio, impacto, interpretación del sitio y educación, aspectos que se relacionan con los lineamientos de manejo y operación de las zonas arqueológicas de acuerdo al INAH.

Para valorar el cumplimiento de los lineamientos que debe de cumplir la apertura y funcionamiento de los sitios arqueológicos también se realizó una investigación de campo en el cual se analizaron las características de los sitios arqueológicos:

1. Importancia del sitio.- Número de edificios visitables, periodo de florecimiento y estilo Arquitectónico

2. Localización.- ubicación geográfica, rutas y distancia, accesibilidad y señalización, horario de funcionamiento, tiempo aproximado del recorrido en la visita.

3. Equipamiento.- bancas, basureros, áreas de descanso, puntos de reunión, bebederos, miradores, senderos, estacionamiento, pasamanos 
y barandales para personas con capacidades diferentes, áreas de resguardo, teléfono, botiquín. Sanitarios, área de administración

4. Señalización.- planos, contenidos en: cédulas informativas, cédulas restrictivas e indicativas, mapas del sitio, materiales de calidad en la señalética.

5. Infraestructura de servicios.- cafetería, nevería, hotel, campamento, restaurant, área para exposición y venta de artesanías, librería, museo de sitio, talleres, aulas (multidisciplinaria), área de esparcimiento.

6. Preservación y Mantenimiento.- sistemas de protección con vallas o vigilancia, andadores, señalización, limpieza general, mantenimiento de sistemas operativos como sanitarios, áreas de vigilancia, administrativas, limpieza de bienes arqueológicos.

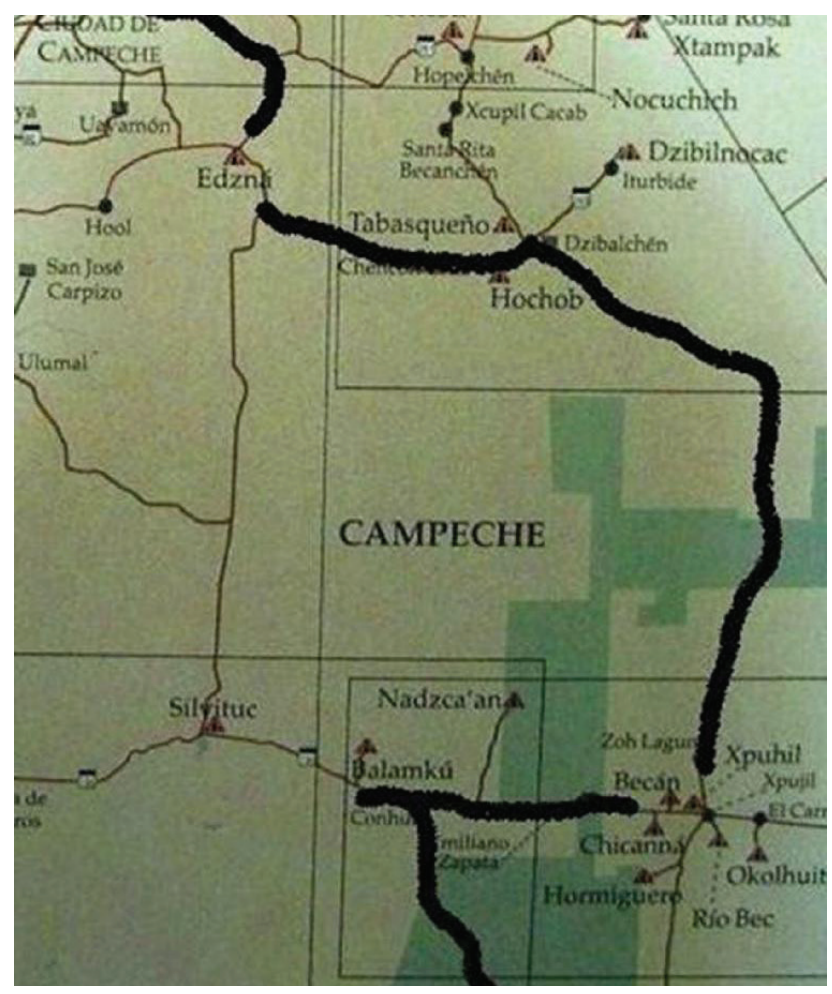

Figura 7. Ruta de sitios arqueológicos seleccionados para su valoración. (Fuente: Juan A. Vázquez García).
Cada una de estas acciones se tomó en consideración dado que se involucran con la puesta en valor del sitio, objetivo de la musealización.

\section{RESULTADOS}

Los sitios arqueológicos de Campeche conforman rutas arqueológicas establecidas por el INAH (Ver Plano 2), estas se localizan en áreas alejadas de las comunidades poblacionales actuales, aún permanecen rodeados de mágicas áreas selváticas que llenan la imaginación del observador las estructuras devoradas por la selva, ofrecen una alternativa para aquellos visitantes que disfrutan de las bellezas de la flora y fauna y las expediciones eco turísticas, pero resulta a veces difícil por su localización, proveerlas de equipamiento, infraestructura y servicios, conservación y mantenimiento, así como la adecuada operación y funcionamiento. Esto no significa que por tales razones, estén a la visita al público con el mínimo equipamiento. Lo que reflejan es la poca planeación de la gestión de este patrimonio cultural. Aseguran la preservación y conservación pero no se aseguran de crear el desarrollo en el propio patrimonio, es decir, se ha planteado la accesibilidad al sitio con una propuesta de visita pública con identificación y difusión, pero no se ha trabajado en la gestión de una conceptualización adecuada en su espacialidad y equipamiento, faltando la parte complementaria de infraestructura de servicios para ofertar estos sitios de manera adecuada con transporte, alojamiento, restauración, guías, etc. (Figura 8), tampoco se involucra a la comunidad para que se concientice y sensibilice de la preservación y cuidado del sitio. En este punto es donde la gestión es de vital importancia y para ello se debe consolidar las alianzas entre los gestores, con los del sector turístico y provean en la puesta en valor también la integración de un desarrollo sustentable de la zona. 


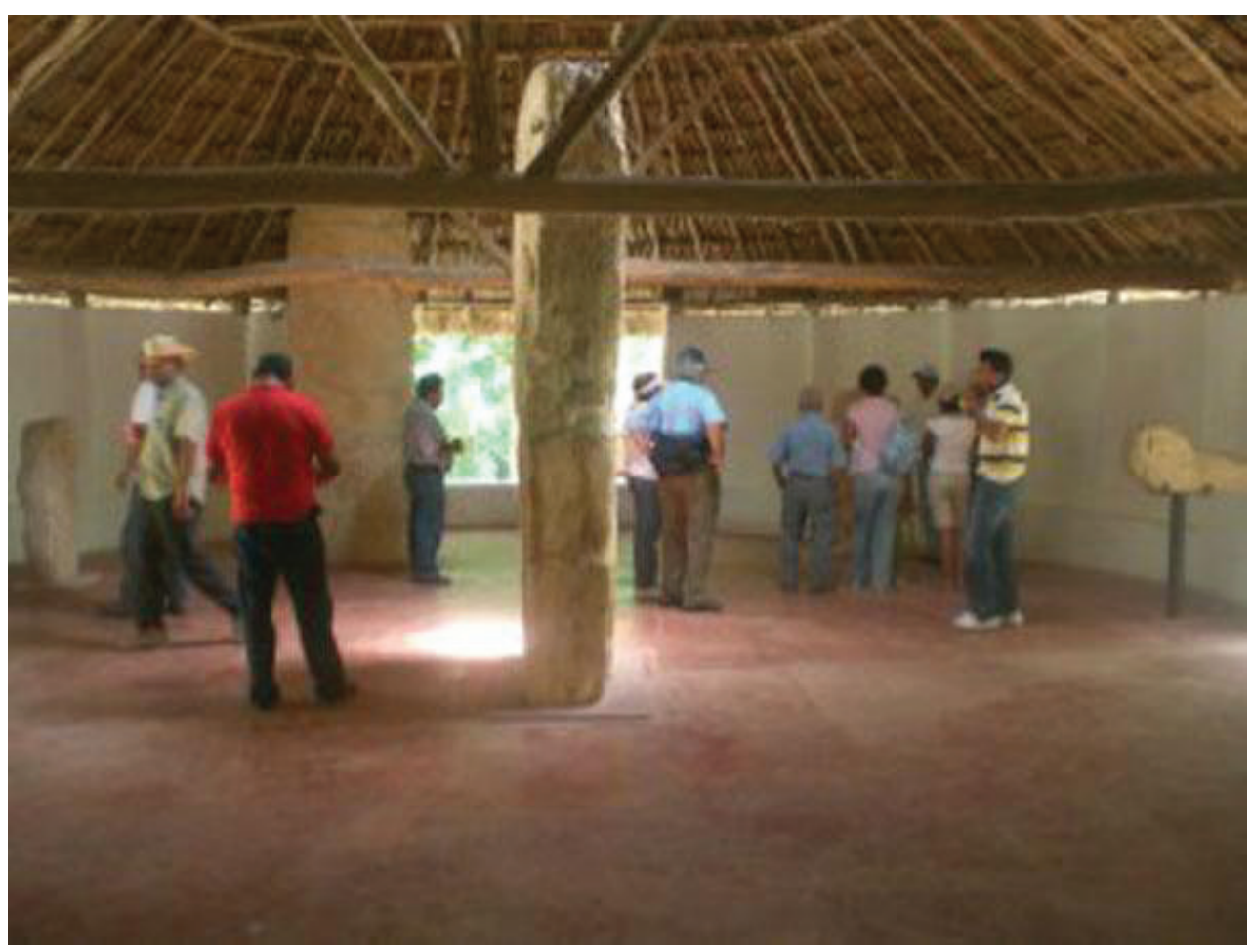

Figura 8. Sala de exposiciones de estelas mayas. Sitio Arqueológico de Edzná (Fuente: Juan A. Vázquez García).

Indiscutiblemente los sitios arqueológicos de Campeche, se abrieron al público por la importancia y características singulares de cada uno de ellos, de acuerdo con la información arqueológica arrojada por los investigadores, variedad de estilos arqueológicos, cerámicas, estelas, tumbas, mascarones, entre otros, demuestran el grado de desarrollo y florecimiento que tuvieron estas ciudades, sin embargo aún estas rutas, no están consolidadas, y no presentan adecuada musealización con un equipamiento acorde a las normas básicas que le permitan al visitante interpretarlas.

Los sitios de Balamkú y Calakmul ${ }^{16}$ (Carrasco \& Colón, 2005: 40-47) de la ruta 4, Becán, Chicanná, y Xpuhil de la ruta 5, y Edzná de la ruta 3 son los sitios con mayor visita pública, con cobertura de accesibilidad carretera. Son sitios arqueológicos donde debe aplicarse una adecuada gestión ya que representan una oportunidad para vincular este patrimonio cultural con el desarrollo de la zona. (Figura 9)

La situación precaria en la que se exponen los sitios al público, con un equipamiento mínimo obliga a un mayor esfuerzo para establecer en ellos toda una accesibilidad espacial y física. Donde los visitantes puedan moverse adecuadamente, para interpretar mejor el sitio, esta adecuación de movilidad im-

14. Según reporta Carrasco y Marinés Colón, en este sitio arqueológico se encuentra la única bóveda de cañón corrido y arco rebajado encontrada en la arquitectura mesoamericana. 
plica para todo tipo de personas incluyendo a las de capacidades diferentes, servicios, higiénicos, áreas para sentarse, etc.
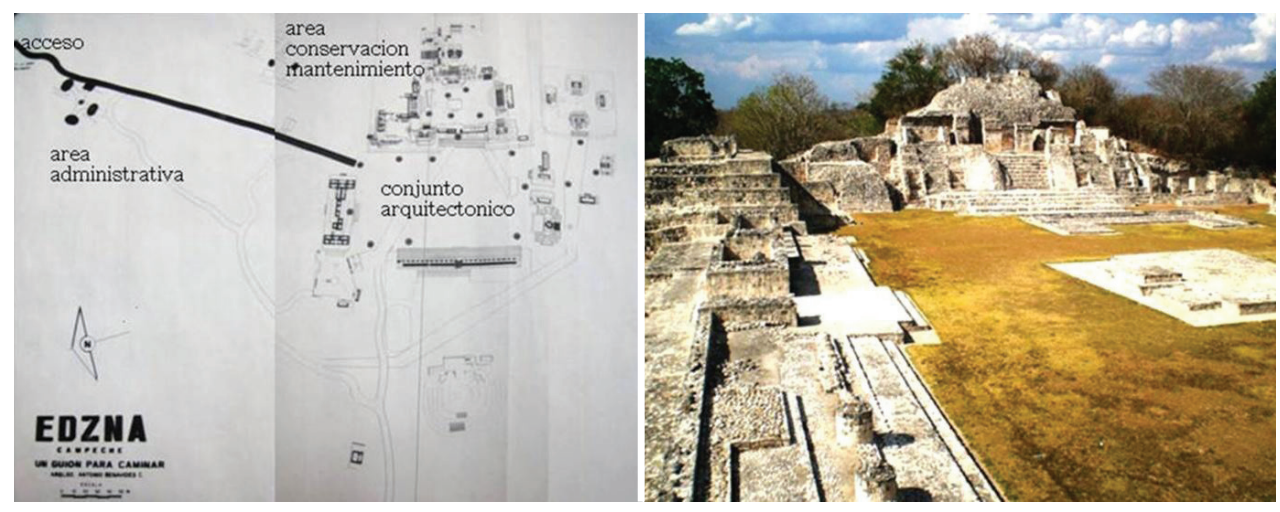

Figura 9. Sitio Arqueológico de Edzná. Conjunto poligonal y vista de la Gran Acrópolis (Fuente: Plano del INAH e imagen de Juan A. Vázquez).

Hoy ante esta situación es más que evidente que para abrir un sitio a la visita pública debe aplicarse lineamientos y requerimientos mínimos en forma enunciativa no limitativa, y deben de vincularse a través de la gestión, la comunidad, el sector privado, y a los profesionales que involucra la puesta en valor, para ser de los sitios un recurso patrimonial con un sentido educativo, turístico y social, con el objetivo de ser permanente en el tiempo y para las futuras generaciones. (Figura 10)

Los sitios arqueológicos de Campeche están abiertos a la vista pública sin el cumplimiento de sus objetivos, sin la visión del sentido educativo sin la gestión adecuada y sin la musealización como un medio para su preservación. No existe una intervención multidisciplinaria en la aplicación metodológica para la apertura del sitio, son los arqueólogos en quien recae por disposición legal y administrativa del INAH, el que ejerzan gestiones y criterios discrecionales en la apertura y puesta en valor de los sitios, lo que supera su capacidad de actuar, reflejándose en la situación en la que se encuentran los diferentes sitios.

Las políticas aplicadas para la apertura de los sitios arqueológicos en Campeche han sido más medidas de protección y conservación ante el saqueo de piezas arqueológicas, que con el verdadero objetivo que se tiene de la puesta en valor con fines educativos, sin consideración alguna de operación y manejo.

Ningún sitio presenta una clara intención y objetivos al presentarlo al público, las respuestas dadas han sido claras medidas de protección ante el saqueo de piezas arqueológicas y el consumo de piedras para la construcción de viviendas por los pobladores. Al no existir un claro objetivo menos se 
puede tener un concepto para la puesta en valor de los sitios, no se logra una clara interpretación por parte de los visitantes. Los sitios no muestran un proceso metodológico que defina funciones, áreas, servicios, creando confusión de lo que se está visitando, un museo fuera de muros, un parque arqueológico o un centro de interpretación arqueológica. Los sitios abiertos al público son simples estructuras con cédulas informativas demasiadas técnicas que no contribuyen al conocimiento del sitio por el visitante. Esto no genera una adecuada interpretación y por ende se desconoce y se desvaloriza el patrimonio arqueológico.

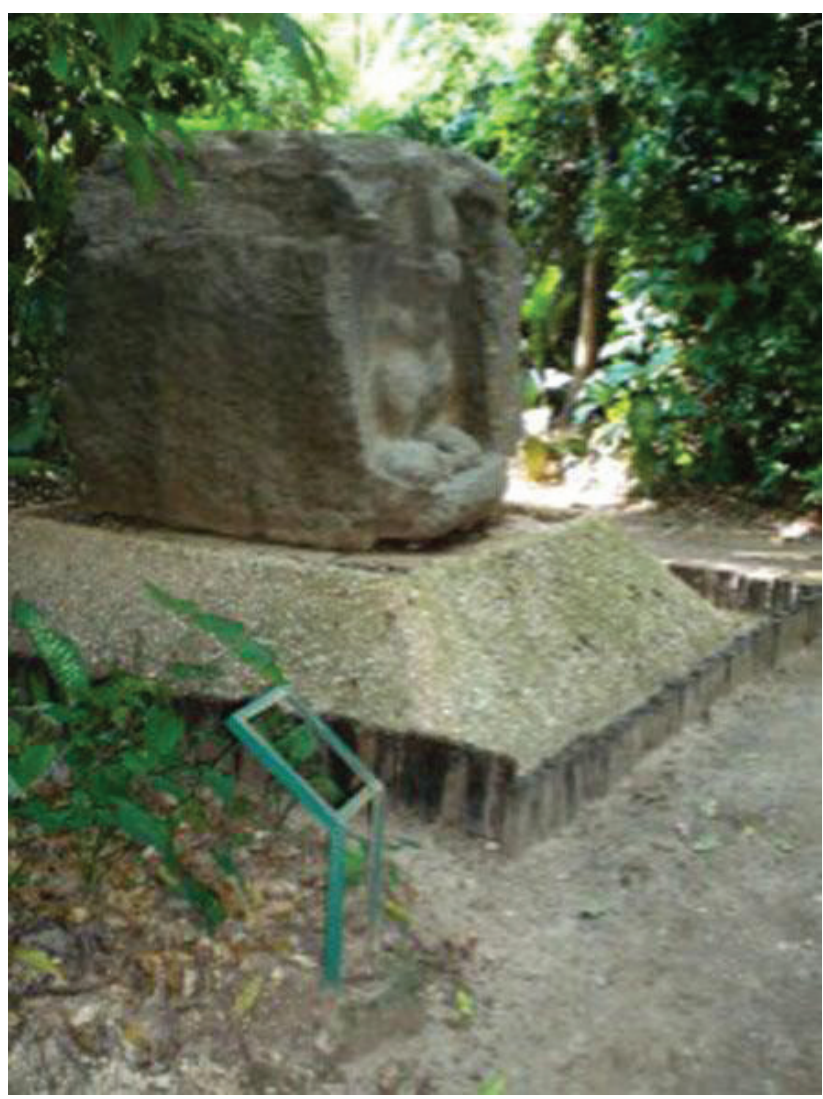

Figura 10. Falta de cédula informativa en exposición de pieza arqueológica (Fuente: Juan A. Vázquez García).

Es importante mencionar que en la fecha que abrieron al público estos sitios, no había lineamientos o requerimientos mínimos para la visita pública, sin embargo esto no indica que los responsables de estos sitios no apliquen la norma actual para mejorar las condiciones en que prevalecen estos sitios para su puesta en valor y mucho menos que no apliquen una gestión que involucre a las comunidades en su integración para un desarrollo sostenible de la zona.

\section{CONCLUSIONES}

Los sitios arqueológicos como un tipo de museo abierto fuera de muros, son uno de los recursos de referencia para la transmisión de la cultura, hacerlos más accesibles al público y conseguir generar experiencias atractivas más allá de la mera observación, es el reto para lograr una sensibilización y concientización con fines de generar conocimiento y valoración de los sitios arqueológicos. Estos espacios deben ser abiertos al público con proyectos museológicos y museográficos, que concluyen en la musealización total del espacio, que incluyan museos de sitio o salas introductorias, infraestructura de servicios y recreación, de manera que lleven a la transformación espacial y física del sitio para mejorar la puesta en valor de este patrimonio, hoy fuertemente vinculado al turismo como un recurso cultural.

El patrimonio arqueológico en México forma parte de las políticas turísticas a nivel nacional, por esta razón urge que se fomente la gestión del patrimonio, para lograr que este binomio; turismo y patrimonio, conformen un esquema vinculado a la comunidad, que incluya planes de manejo. Estos planes de manejo, se tienen que aplicar a las políticas de conservación y protección del patrimonio arqueológico, situación de ausencia para nuestro caso, al ser evidente la falta de comunicación de los gestores responsables del patrimonio arqueológico, (los arqueólogos) con los sectores estatales e inter-institucionales, académicos y empresariales, que permiten el desarrollo local de las comunidades en el mejoramiento de la musealización en los sitios arqueológicos. Resulta necesario activar este ejercicio de diálogo intersectorial, que involucre acciones 
tendientes a consolidar el ejercicio de la gestión cultural entre profesionales y las comunidades donde se expresan estos recursos culturales, con el fin de buscar las herramientas diseñadas para la apropiación de recursos para proyectos específicos, dependiendo del grado de madurez organizacional, de la participación comunitaria y que sean estas interpretadas adecuadamente por los profesionales, gestores y funcionarios para llegar a un desarrollo coherente de la políticas turística y cultural.

Los sitios son responsabilidad del INAH pero al mismo tiempo es responsabilidad de todos, no solo porque la ley así lo establezca, sino porque son la base de nuestra identidad como nación, cuyos retos futuros y la solución que le demos, dependerá de lo hayamos protegido y conservado. Los ciudadanos no pueden proteger lo que no conocen y menos lo que no valoran como propio, hoy cualquier ciudadano de este país o extranjero puede visitar un sitio arqueológico en Campeche, pero más allá de observar y tomarse la foto, está la intención de educarse, de aprender, de valorar e identificar la historia de los antepasados, para reconocerse en ella y poder preservar y conservar la identidad que se manifiesta físicamente. Es precisamente con la finalidad de proteger y conservar, que muchos de los sitios arqueológicos de Campeche se abrieron a la visita al público, de esta manera se custodiaba la zona del constante saqueo, sin embargo la forma de mostrarlo y exhibirlo no ha sido la adecuada. El tema resulta por demás complejo, si se toman acciones para la musealización de los mismos, tomando en consideración la visión de los sitios como la de un museo fuera de muros.

La adecuada musealización debe basarse en una metodología con proyectos museológicos y museográficos, con una intención clara de lo que se quiere mostrar y cómo se debe mostrar con objetivos claros y definidos como el de todo museo. De esta manera, la musealización o forma de exhibirse al público cualquier sitio puede convertirse en la vía para la sensibilización y con- cientización del patrimonio que lleve a cualquier ciudadano a valorar, proteger, conservar y mantener su patrimonio, que involucre a las comunidades donde se ubican estos sitios y generen el desarrollo sostenible de los sitios y las comunidades que forman parte integral del paisaje.

En los últimos diez años para el INAH, el reto será institucionalizar una nueva visión de la gestión y el manejo de sitios arqueológicos, mediante la construcción de políticas que buscan la apertura de espacios de participación y concertación con los distintos actores sociales y gubernamentales para dinamizar, social y económicamente, los bienes culturales, al tiempo de fortalecer los principios técnicos y de normatividad para su preservación y conservación.

En ese marco, la planeación para la conservación, el manejo y la gestión del patrimonio cultural, ha presentado sin duda alguna como herramienta fundamental, establecer lineamientos para la apertura de sitios arqueológicos a la visita pública, para la planeación y operación de sitios con visita pública y para la elaboración de proyectos arquitectónicos de equipamiento y señalización en zonas arqueológicas.

El INAH hoy se ha visto rebasado para la aplicación de esta normatividad. Aspectos como la centralización del Instituto, la capacidad de carga de funciones en su estructura administrativa, las ideologías que se contraponen al interior de la institución, el sindicalismo, la burocracia, la falta de gestión, el desinterés multidisciplinario en sus profesiones, la falta de vinculación con las comunidades, son elementos identificados en el transcurso de esta investigación que influyen en el funcionamiento para la aplicación de la norma.

Aunado a esto la renuencia a la transformación y el cambio, ha llevado directamente al incumplimiento de la normatividad en los sitios arqueológicos, donde directamente debe aplicarse y de esta manera fortalecer los objetivos para preservar el patrimonio arqueológico. 


\section{REFERENCIAS BIBLIOGRÁFICAS}

Ballart , J. \& Juan, J. (2001). Gestión del Patrimonio Cultural. Barcelona: Ariel, p.23

Campaña, L. E. (2005). Campeche. Arqueología Mexicana. Vol. XIII (75): 78-85

Carrasco V., R. \& Colón M. 2005. El reino de kaan y la antigua ciudad maya de Calakmul. Arqueología mexicana, Vol XIII (75): 40-47

CONACULTA. Red de zonas arqueológicas. En http://www.inah.gob.mx/zonas-arqueologicas Consejo internacional de Museos (ICOM). (1995). Estatutos ICOM. Recuperado de: http// icom.museum/hist_def_eng.html (consultado el 15 de noviembre de 2010) .(2007). Estatutos del ICOM. Recuperado de: http://icom.museum/fileadmin/user upload/pdf/Statuts/statutes_spa.pdf (consultado el 15 de noviembre de 2010 en Mérida, Yucatán)

Instituto Latinoamericano de Museos ILAM, Nueve años de trabajo: ILAM 1997 - 2006. San José: Ediciones ILAM, 2007.

Instituto Nacional de Antropología e Historia (INAH). Catálogo de sitios y Monumentos Arqueológicos última actualización en agosto de 2013. Recuperado de: http://www.inah.gob. $\mathrm{mx}$ /zonas-arqueologicas

(2006). Lineamientos para la elaboración de proyectos arquitectónicos, equipamiento y señalización en zonas arqueológicas.
Recuperado de: http://www.normateca.inah. gob.mx/documents/066.pdf y http://www.normateca.inah.gob.mx/documents/070.pdf (consultado el 20 de octubre de 2010)

Lasheras, J. A. \& M. Hernández (2006). Explicar o contar. La selección temática del discurso histórico en la musealización. III Congreso Internacional de Musealización de Yacimientos Arqueológicos. Ayuntamiento de Zaragoza: 129-136

Lavert Proyectos Culturales, Musealización. En http://www.lavert.net/Expertos-en/Musealización (consultado el 10 de diciembre de 2010 en Mérida, Yucatán)

Ley Federal sobre Monumentos y Zonas Arqueológicas, Artísticos e Históricos. Diario Oficial de la Federación, México, 6 de mayo de 1972: p. 1-15

Ley General de Museos. Diario Oficial de la Federación, México, 26 de septiembre de 1988 Manual general de organización del Instituto Nacional de Antropología e Historia. Objetivos estratégicos. Diario Oficial de la Federación, México, 17 de enero de 2011

Peña C., A. (1999). Campeche. En Historia mínima de Campeche (36-74). Gobierno del Estado de Campeche.

Querol, M. (2010). Manual de Gestión del Patrimonio Cultural. Madrid: Akal, p.51-57

Santacana, J. \& Serrat, N. (2005). Museografia didáctica. Barcelona: Ariel, p.430-431 